\title{
Process Optimization \\ of the Synthesis Nanoporous Carbon Materials with Thermo-Chemical Activation of Lignin Birch Wood
}

\author{
Ivan P. Ivanov and Nadezhda M. Mikova* \\ Institute of Chemistry and Chemical Technology SB RAS \\ 50/24 Akademgorodok, Krasnoyarsk, 660036, Russia
}

Received 08.10.2015, received in revised form 11.12.2015, accepted 18.03.2016

\begin{abstract}
As a result of dispersion analysis of the experimental data the mathematical model of process thermochemical activation of lignin, formed during catalytic delignification of birch wood, the potassium hydroxide on the values of the parameters of porous structure of nanoporous carbon materials was obtained. It was determined that the process in optimal conditions allows to obtain of the lignin based carbon materials with specific surface of more than $2500 \mathrm{~m} 2 / \mathrm{g}$ and a pore volume of $1.4 \mathrm{~cm} 3 / \mathrm{g}$. The obtained nanoporous carbon materials possess high sorption capacity for benzene (1.1 g/g), exceeding the capacity of domestic and foreign commercial carbon sorbents in 3-6 times.
\end{abstract}

Keywords: birch lignin, pore volume, thermal and chemical activation of nanoporous carbon material, process optimization mathematical model.

DOI: $10.17516 / 1998-2836-2016-9-1-78-88$.

(C) Siberian Federal University. All rights reserved

* Corresponding author E-mail address: ivanov@icct.ru 


\title{
Оптимизация процесса синтеза нанопористых углеродных материалов при термохимической активации лигнина древесины березы
}

\author{
И.П. Иванов, Н.М. Микова \\ Институт химии и химической технологии СО РАН \\ Россия, 660036, Красноярск, Академгородок, 50-24
}

\begin{abstract}
В результате дисперсионного анализа экспериментальных данных получена математическая модель прочесса термохимической активачии лигнина, образующегося при каталитической делигнификаиии древесины березы гидроксидом калия, на значения параметров пористой структуры получаемых нанопористых углеродных материалов. Установлено, что проведение прочесса в оптимальных условиях позволяет получать на основе лигнина углеродные материаль с удельной поверхностью более $2500 \mathrm{~m}^{2} / 2$ и объемом пор $1,4 \mathrm{~cm}^{3} / 2$. Полученнье нанопористые углеродные материалы обладают высокой сорбиионной емкостью по бензолу (1,1 г/2), превосходямую емкость отечественных и зарубежных коммерческих углеродных сорбентов в 3-6 раз.
\end{abstract}

Ключевые слова: лигнин березы, объем пор, термохимическая активачия, нанопористый углеродный материал, оптимизация процесса, математическая модель.

\section{Введение}

Мировой опыт свидетельствует, что производство и потребление активных углей (пористых углеродных материалов - ПУМ) имеет устойчивую тенденцию к росту. Мировое потребление активированных углей составляет около 1,1 млн т в год и продолжает расти на $9 \%$ в год [1]. При этом основное количество активированных углей (80-85 \%) производится из невозобновляемых угольных ресурсов [2].

Широкий ассортимент ПУМ можно получать на основе крупнотоннажных отходов химической и механической переработки древесины: опилок, коры, отходов лесозаготовок и, в частности, лигнинов.

Лигнин является вторым основным после целлюлозы природным сырьем [3] и наиболее распространенным ароматическим (фенольным) полимером [4], основной функцией которого служит цементация целлюлозных волокон в растениях. Как правило, полученные отходы черного щелока, сбрасываемые бумажными фабриками в больших количествах, представляют серьезную проблему при их утилизации $[5,6]$.

С другой стороны, рост суммарного производство лигнина (более 50 млн т/г) сопровождается увеличением интереса к разработке новых экономически эффективных технологий его переработки. В настоящее время большая часть лигнина, произведенного целлюлознобумажной промышленностью, используется в качестве топлива. Хотя есть и другие незначительные направления его использования, такие как клей или дубитель, никаких серьезных крупномасштабных технологий его применения пока не найдено [3, 7-9]. 
Возможности применения лигнина для получения ПУМ были широко изучены для различных видов (типов) технических лигнинов, в частности щелочных лигнинов (образуется от варки древесины в растворах щелочей), лигносульфонатов (сульфитная варка древесины) и гидролизных лигнинов (кислотный гидролиз из древесины) [10, 11].

На примере выполненных в Институте химии и химической технологии СО РАН (Красноярск) работ рассмотрены актуальные направления в совершенствовании способов химической переработки растительной биомассы и в создании новых методов комплексной утилизации ее основных компонентов: полисахаридов, лигнина, экстрактивных веществ [12]. Приведены примеры разрабатываемых процессов утилизации древесных отходов с получением ценных химических соединений (левулиновой кислоты, глюкозы, ксилозы, ароматических альдегидов, биологически активных веществ), востребованных материалов (целлюлозы, биодеградируемых полимеров, пористых углеродных материалов) и жидких топлив.

Актуальность проведения исследований по разработке новых технологий получения недорогих и эффективных ПУМ обусловлена также их потребностью в самых разнообразных отраслях промышленности для очистки технологических растворов, при синтезе лекарственных препаратов, всевозможных напитков, в крахмалопаточном производстве, для очистки воды и в других традиционных для адсорбционных технологий отраслях. Кроме того, в настоящее время появляются принципиально новые направления применения активированных углей, а именно при изготовлении суперконденсаторов, аккумуляторных батарей высокой мощности, в которых наряду с электролитами большое влияние на мощность и скорость зарядки имеет внутренняя поверхность углеродных материалов.

В настоящее время при синтезе ПУМ находят все большее распространение методы химической активации. Это объясняется тем, что они позволяют получать адсорбенты со строго заданными параметрами пористой структуры и с высокими кинетическими показателями адсорбционных процессов. Также к преимуществам способа следует отнести сравнительно короткое время активирования сырья, большой выход углеродного остатка, высокие адсорбционные свойства активного угля.

Цель данной работы - математическое моделирование и оптимизация условий процесса термохимической активации лигнина древесины березы гидроксидом калия и определение условий, обеспечивающих получение нанопористых углеродных материалов с максимальной удельной поверхностью, объемом пор и активностью при сорбции бензола.

\section{Экспериментальная часть}

Настоящая методика оптимизации осуществлена с целью математического моделирования условий, обеспечивающих наилучшие условия для проведения процесса термохимической активации лигнина березы, для получения нанопористых углеродных материалов с удельной поверхностью не менее $2500 \mathrm{~m}^{2} / \Gamma$, объемом пор более $0,5 \mathrm{~cm}^{3} / \Gamma$ и максимальной адсорбционной активностью по бензолу.

Дисперсионный анализ и математическая обработка результатов была выполнена средствами пакета прикладных программ Statgraphics Centurion XVI, блок DOE (Design of Experiment), процедура Multi-Factor Categorical [13]. 
Процесс получения нанопористых углеродных материалов из лигнина древесины березы включает термохимическую активацию лигнина в плаве гидроксида калия, промывку его водой, нейтрализацию соляной кислотой получаемых углеродных материалов и их последующую сушку. Процесс термохимической активации вносит основной вклад в формирование пористой структуры и сорбционных свойств нанопористых углеродных материалов на основе лигнина.

В качестве активатора применяли гидроксид калия в твердом виде. Получение углеродных материалов проводили смешиванием исходного сырья с измельченной щелочью в массовом соотношении 1:1 - 1:4, последующим нагреванием подготовленной смеси в инертной атмосфере (аргон) при скорости подъема температуры от 1 до $20^{\circ} \mathrm{C} / \mathrm{Mин} \mathrm{до} 800{ }^{\circ} \mathrm{C}$ и изотермической выдержкой в течение 1 ч.

Одной из основных задач выполненного дисперсионного анализа являлось определение влияния независимых факторов (соотношение лигнина и щелочи $(\mathrm{KOH})$ и интенсивности нагрева) на значения выходных параметров: удельная поверхность, объем пор и сорбция бензола нанопористыми углеродными материалами (НУМ), полученными в процессе термохимической активации лигнина древесины березы гидроксидом калия. Температура активации $\left(800{ }^{\circ} \mathrm{C}\right)$ и продолжительность изотермической выдержки (1 ч) оставались постоянными во всех опытах.

В качестве независимых переменных условий процесса выбрали наиболее важные факторы, определенные на основании априорной информации и результатов предварительных опытов: весовое отношение КОН/лигнин $\left(\mathrm{X}_{1}, \Gamma / \Gamma\right)$ и интенсивность нагрева $\left(\mathrm{X}_{2},{ }^{\circ} \mathrm{C} / \mathrm{мин}\right)$ процесса.

Результаты опытов характеризовали следующими выходными параметрами:

$$
\begin{aligned}
& \mathrm{Y}_{1} \text { - удельная поверхность, } \mathrm{M}^{2} / \Gamma \text {; } \\
& \mathrm{Y}_{2} \text { - объем пор, } \mathrm{cm}^{3} / \Gamma ; \\
& \mathrm{Y}_{4} \text { - сорбция бензола, г/г. }
\end{aligned}
$$

Экспериментальные данные, показывающие интервалы варьирования факторов и их влияние на выходные параметры, приведены в табл. 1.

Таблица 1. Условия и результаты экспериментов

\begin{tabular}{|c|c|c|c|c|}
\hline \multicolumn{2}{|c|}{ Условия опытов } & \multicolumn{3}{|c|}{ Результаты опытов } \\
\hline $\mathrm{X}_{1}, \Gamma / \Gamma$ & $\mathrm{X}_{2},{ }^{\circ} \mathrm{C} /$ мин & $\begin{array}{c}\text { Удельная } \\
\text { поверхность, } \mathrm{Y}_{1}, \mathrm{M}^{2} / \Gamma\end{array}$ & $\begin{array}{c}\text { Объем пор, } \mathrm{Y}_{2}, \\
\text { см}^{3} / \Gamma\end{array}$ & $\begin{array}{c}\text { Сорбция бензола, } \\
\mathrm{Y}_{4}, \Gamma / \Gamma\end{array}$ \\
\hline 1 & 2 & 3 & 4 & 5 \\
\hline $1: 1$ & 5 & 972 & 0,68 & 0,47 \\
\hline $1: 2$ & 5 & 1548 & 0,85 & 0,90 \\
\hline $1: 3$ & 5 & 2228 & 1,35 & 0,52 \\
\hline $1: 4$ & 5 & 1434 & 0,81 & 0,97 \\
\hline $1: 3$ & 1 & 2586 & 1,42 & 0,90 \\
\hline $1: 3$ & 5 & 2228 & 1,35 & 1,03 \\
\hline $1: 3$ & 10 & 2085 & 1,31 & 1,05 \\
\hline $1: 3$ & 20 & 1997 & 1,39 & \\
\hline
\end{tabular}




\section{Результаты и обсуждение}

Анализ влияния условий термохимической активачии лигнина

древесины березы гидроксидом калия на развитие удельной поверхности

нанопористых углеродных материалов

Дисперсионный анализ и математическое моделирование было проведено для массива экспериментальных данных табл. 1. Экспериментально наблюдаемый характер зависимостей удельной поверхности от условий термохимической активации позволил выбрать следующие факторы для проведения дисперсионного и регрессионного анализов: соотношение лигнина и КОН $\left(\mathrm{X}_{1}\right)$ и интенсивность нагрева $\left(\mathrm{X}_{2}\right)$.

Результаты дисперсионного анализа для удельной поверхности НУМ отражены в табл. 2.

Приведенные в табл. 2 значения F-Ratio и P-Value демонстрируют, что максимальное влияние на удельную поверхность оказывает фактор соотношения лигнина и щелочи в реакционной смеси $\left(\mathrm{X}_{1}\right)$.

Был рассчитан коэффициент детерминации $\left(\mathrm{R}^{2}=90,7 \%\right)$, близкий по смыслу к коэффициенту множественной корреляции между выходным параметром $\left(\mathrm{Y}_{1}\right)$ и переменными факторами.

Методом регрессионного анализа получена математическая модель, описывающая зависимость удельной поверхности НУМ из лигнина березы $\left(\mathrm{Y}_{1}\right)$ от переменных факторов, представленных в табл. 2.

Таблица 2. Результаты дисперсионного анализа для удельной поверхности $\left(\mathrm{Y}_{1}\right)$

\begin{tabular}{|c|c|c|c|c|c|}
\hline $\begin{array}{c}\text { Источник } \\
\text { дисперсии }\end{array}$ & $\begin{array}{c}\text { Сумма } \\
\text { квадратов }\end{array}$ & $\begin{array}{c}\text { Число степеней } \\
\text { свободы }\end{array}$ & $\begin{array}{c}\text { Средний } \\
\text { квадрат }\end{array}$ & F-Ratio & P-Value \\
\hline $\mathrm{A}: \mathrm{X}_{1}$ & 290394,0 & 1 & 290394,0 & 4,37 & 0,1276 \\
\hline $\mathrm{B}: \mathrm{X}_{2}$ & 3978,92 & 1 & 3978,92 & 0,06 & 0,8224 \\
\hline $\mathrm{AA}$ & 925211,0 & 1 & 925211,0 & 13,93 & 0,0335 \\
\hline $\mathrm{BB}$ & 202780,0 & 1 & 202780,0 & 3,05 & 0,1789 \\
\hline $\mathrm{R}^{2}, \%$ & 90,7 & & & & \\
\hline
\end{tabular}

Примечание. F-Ratio - дисперсионное отношение Фишера; P-Value - уровень значимости.

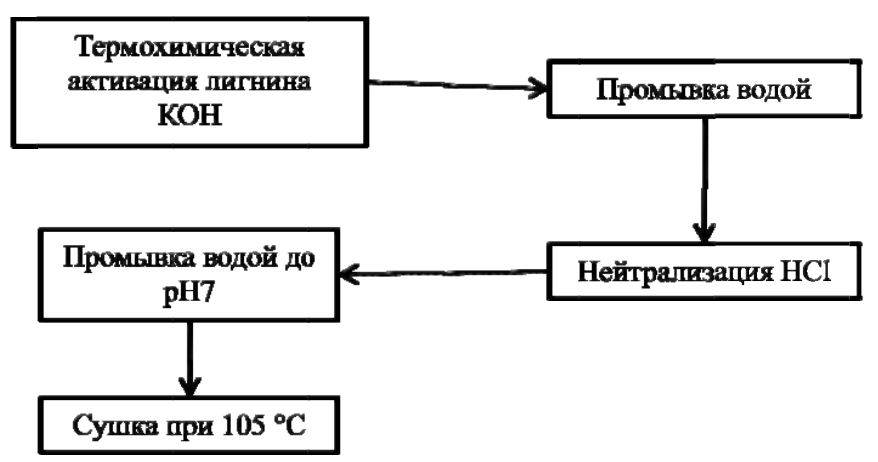

Рис. 1. Схема процесса термохимической активации лигнина древесины березы гидроксидом калия

$$
-82-
$$


Уравнение регрессии, аппроксимирующее зависимость $\mathrm{Y}_{1}$ от $\mathrm{X}_{1}$ и $\mathrm{X}_{2}$, имеет следующий вид:

$$
Y_{1}=-160,43+2296,03 X_{1}-122,566 X_{2}-412,301 X_{1}^{2}+5,63002 X_{2}^{2}
$$

Рисунок 2 иллюстрирует сравнение экспериментальных значений выходного параметра $Y_{1}$ со значениями, прогнозируемыми полученной математической моделью (уравнение 1).

Незначительный разброс экспериментальных точек вокруг прямой указывает на удовлетворительные прогностические свойства полученного уравнения регрессии. Этот результат коррелирует со значением коэффициента детерминации $\mathrm{R}^{2}=90,7$.

На рис. 3 приведены двумерные сечения трехмерной поверхности отклика, наглядно показывающие влияние переменных факторов на выходной параметр $Y_{1}$.

На основании полученной математической модели можно рассчитать условия термохимической активации лигнина древесины березы, позволяющие получить НУМ с максимальной удельной поверхностью $\left(\mathrm{Y}_{1}\right)$. Было установлено, что максимальное значение $\mathrm{Y}_{1}=2519 \mathrm{~m}^{2} / \Gamma$ в

Plot of y1

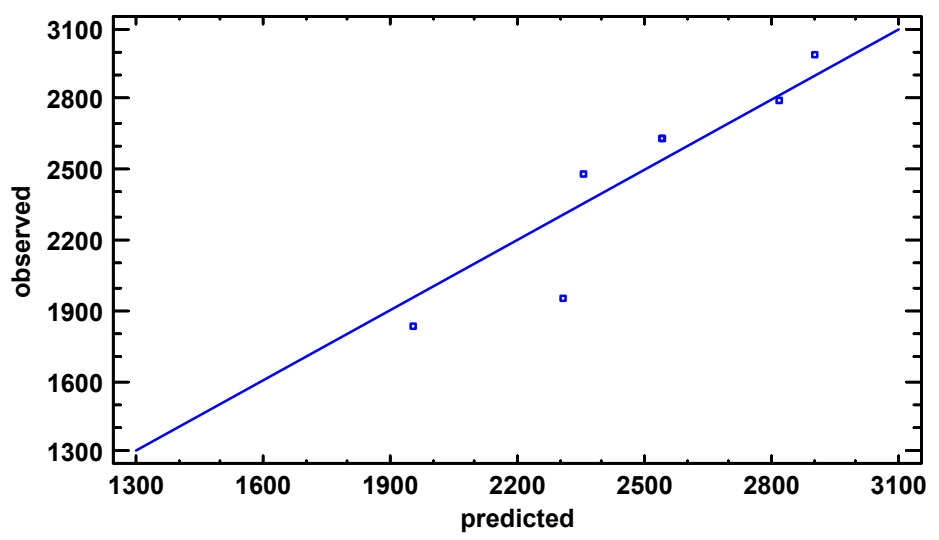

Рис. 2. Сравнение экспериментальных и расчетных значений $Y_{1}$ НУМ из лигнина древесины березы

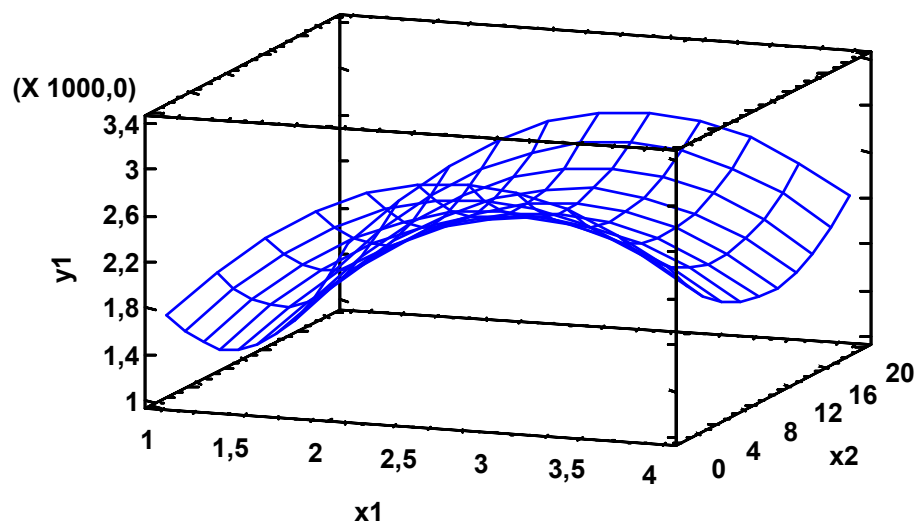

Рис. 3. Поверхность отклика зависимости удельной поверхности ( $\left.\mathrm{Y}_{1}\right)$ от условий процесса $\mathrm{X}_{1}$ и $\mathrm{X}_{2}$ 
пределах изученного факторного пространства прогнозируется при следующих условиях: соотношение КОН/лигнин 2,78 (по массе) и интенсивность нагрева $1^{\circ} \mathrm{C} / \mathrm{Mин.}$

Анализ влияния условий термохимической активаџии

лигнина древесины березы гидроксидом калия

на объем пор нанопористых углеродных материалов

Анализ влияния условий получения НУМ на объем пор ( $\left.\mathrm{Y}_{2}\right)$ был проведен на основе экспериментальных данных табл. 1. Дисперсионный и регрессионный анализы проводили для следующего ряда факторов: соотношение лигнина и КОН $\left(\mathrm{X}_{1}\right)$ и интенсивность нагрева $\left(\mathrm{X}_{2}\right)$.

Методом регрессионного анализа получена математическая модель, описывающая зависимость объема пор НУМ из лигнина березы $\left(\mathrm{Y}_{2}\right)$ от переменных факторов, представленных в табл. 3.

Приведенные в табл. 3 значения F-Ratio и P-Value показывают, что максимально влияет на объем пор фактор соотношения лигнина и щелочи в реакционной смеси $\left(\mathrm{X}_{1}\right)$.

Был рассчитан коэффициент детерминации $\left(\mathrm{R}^{2}=79,1 \%\right)$, близкий по смыслу к коэффициенту множественной корреляции между выходным параметром $\left(\mathrm{Y}_{2}\right)$ и переменными факторами. Относительно невысокая степень детерминации может быть следствием неучитываемого влияния других стадий обработки лингина (промывок водой и нейтрализации), «экспериментального шума» (за счет, например, влияния неконтролируемых, случайные параметров) и др.

Методом регрессионного анализа получена математическая модель, описывающая зависимость удельной поверхности НУМ из лигнина березы $\left(\mathrm{Y}_{2}\right)$ от переменных факторов, представленных в табл. 3.

Уравнение регрессии, аппроксимирующее зависимость $\mathrm{Y}_{2}$ от $\mathrm{X}_{1}$ и $\mathrm{X}_{2}$, имеет следующий вид:

$$
Y_{2}=-0,328564+1,27049 X_{1}-0,0351144 X_{2}-0,231943 X_{1}^{2}+0,00177691 X_{2}^{2} .
$$

Рисунок 4 иллюстрирует сравнение экспериментальных значений выходного параметра $\mathrm{Y}_{2}$ со значениями, прогнозируемыми полученной математической моделью (уравнение 2).

Разброс экспериментальных точек вокруг прямой указывает на удовлетворительные прогностические свойства полученного уравнения регрессии. Этот результат коррелирует со зна-

Таблица 3. Результаты дисперсионного анализа для объема пор ( $\left.\mathrm{Y}_{2}\right)$

\begin{tabular}{|c|c|c|c|c|c|}
\hline $\begin{array}{c}\text { Источник } \\
\text { дисперсии }\end{array}$ & $\begin{array}{c}\text { Сумма } \\
\text { квадратов }\end{array}$ & $\begin{array}{c}\text { Число степеней } \\
\text { свободы }\end{array}$ & $\begin{array}{c}\text { Средний } \\
\text { квадрат }\end{array}$ & F-Ratio & P-Value \\
\hline $\mathrm{A}: \mathrm{X}_{1}$ & 0,0647927 & 1 & 0,0647927 & 1,40 & 0,3216 \\
\hline $\mathrm{B}: \mathrm{X}_{2}$ & 0,00102544 & 1 & 0,00102544 & 0,02 & 0,8910 \\
\hline $\mathrm{AA}$ & 0,292801 & 1 & 0,292801 & 6,34 & 0,0863 \\
\hline $\mathrm{BB}$ & 0,0201993 & 1 & 0,0201993 & 0,44 & 0,5557 \\
\hline $\mathrm{R}^{2}, \%$ & \multicolumn{7}{|c|}{} \\
\hline
\end{tabular}

Примечание. F-Ratio - дисперсионное отношение Фишера; P-Value - уровень значимости.

$$
-84-
$$




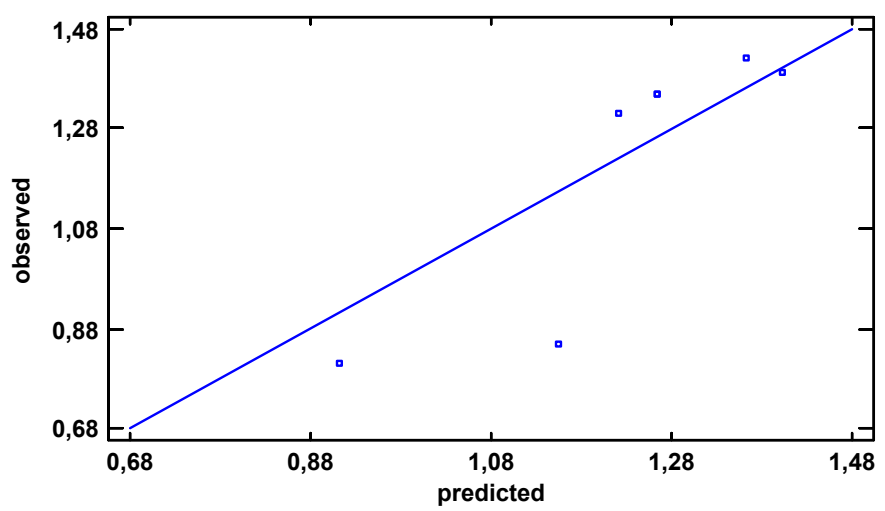

Рис. 4. Сравнение экспериментальных и расчетных значений объема пор $\left(\mathrm{Y}_{2}\right)$ НУМ из лигнина древесины березы

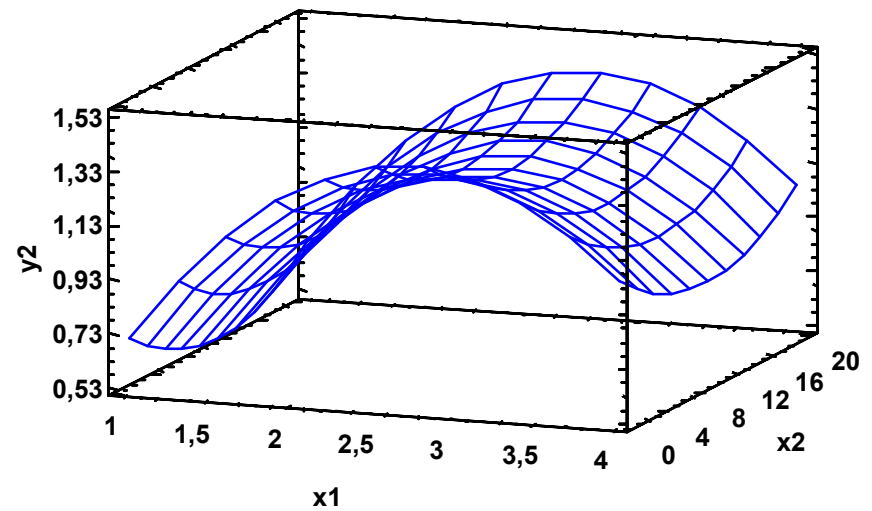

Рис. 5. Поверхность отклика зависимости объема пор $\left(\mathrm{Y}_{2}\right)$ от условий процесса $\mathrm{X}_{1}$ и $\mathrm{X}_{2}$

чением коэффициента детерминации $\mathrm{R}^{2}=79,1$. Очевидно, разброс точек обусловлен теми же причинами, что и полученное значение $\mathrm{R}^{2}$.

На рис. 5 приведены двумерные сечения трехмерной поверхности отклика, наглядно демонстрирующие влияние переменных факторов на выходной параметр $\mathrm{Y}_{2}$.

Рассчитаны условия термохимической активации лигнина древесины березы, позволяющие получить НУМ с максимальным объемом пор $\left(\mathrm{Y}_{2}\right)$. Было установлено, что максимальное значение $\mathrm{Y}_{2}=1,42 \mathrm{~m}^{3} / \Gamma$ в пределах изученного факторного пространства прогнозируется при следующих условиях: соотношение КОН/лигнин 2,74 (по массе) и интенсивности нагрева $20^{\circ} \mathrm{C} /$ мин.

Анализ влияния условий термохимической активации лигнина

древесины березы гидроксидом калия

на сорбиию бензола нанопористыми углеродными материалами

Анализ влияния условий получения НУМ на сорбцию бензола $\left(\mathrm{Y}_{4}\right)$ был проведен на основе экспериментальных данных табл. 1. Дисперсионный и регрессионный анализы про- 
водили для следующего ряда факторов: соотношение лигнина и КОН $\left(\mathrm{X}_{1}\right)$ и интенсивность нагрева $\left(\mathrm{X}_{2}\right)$.

Методом регрессионного анализа получена математическая модель, описывающая зависимость сорбции бензола НУМ из лигнина березы $\left(\mathrm{Y}_{4}\right)$ от переменных факторов, представленных в табл. 4.

Приведенные в табл. 4 значения F-Ratio и P-Value показывают, что сравнительно одинаково влияние на удельную поверхность фактора соотношения лигнина и щелочи в реакционной смеси $\left(\mathrm{X}_{1}\right)$ и интенсивности нагрева реакционной смеси $\left(\mathrm{X}_{2}\right)$.

Был рассчитан коэффициент детерминации $\left(\mathrm{R}^{2}=70,4\right.$ \%), близкий по смыслу к коэффициенту множественной корреляции между выходным параметром $\left(\mathrm{Y}_{4}\right)$ и переменными факторами. Относительно невысокая степень детерминации может быть следствием конкурирующего влияния факторов соотношения лигнина и щелочи в реакционной смеси $\left(\mathrm{X}_{1}\right)$ и интенсивности нагрева реакционной смеси $\left(\mathrm{X}_{2}\right)$.

Методом регрессионного анализа получена математическая модель, описывающая зависимость удельной поверхности НУМ из лигнина березы $\left(\mathrm{Y}_{4}\right)$ от переменных факторов, представленных в табл. 4.

Уравнение регрессии, аппроксимирующее зависимость $\mathrm{Y}_{4}$ от $\mathrm{X}_{1}$ и $\mathrm{X}_{2}$, имеет следующий вид:

$$
\mathrm{Y}_{4}=-0,342249+0,902639 \mathrm{X}_{1}-0,00861315 \mathrm{X}_{2}-0,164563 \mathrm{X}_{1}^{2}+0,000900014 \mathrm{X}_{2}^{2} .
$$

Рисунок 6 иллюстрирует сравнение экспериментальных значений выходного параметра $\mathrm{Y}_{4}$ со значениями, прогнозируемыми полученной математической моделью (уравнение 3), показывает разброс экспериментальных точек вокруг прямой экспериментальных и прогностических свойств полученного уравнения регрессии. Этот результат коррелирует со значением коэффициента детерминации $\mathrm{R}^{2}=70,4$.

На рис. 7 приведены двумерные сечения трехмерной поверхности отклика, наглядно иллюстрирующие влияние переменных факторов на выходной параметр $\mathrm{Y}_{4}$.

Рассчитаны условия термохимической активации лигнина древесины березы, позволяющие получить НУМ с максимальной сорбцией бензола $\left(\mathrm{Y}_{4}\right)$. Было установлено, что максимальное значение сорбции бензола при этих условиях $\left(\mathrm{Y}_{4}=1,08\right.$ г/г) в пределах изученного факторного пространства прогнозируется при следующих условиях: соотношение КОН/лигнин 4,0 (по массе) и интенсивности нагрева $20^{\circ} \mathrm{C} /$ мин.

Таблица 4. Результаты дисперсионного анализа для сорбции бензола $\left(\mathrm{Y}_{4}\right)$

\begin{tabular}{|c|c|c|c|c|c|}
\hline $\begin{array}{c}\text { Источник } \\
\text { дисперсии }\end{array}$ & $\begin{array}{c}\text { Сумма } \\
\text { квадратов }\end{array}$ & $\begin{array}{c}\text { Число степеней } \\
\text { свободы }\end{array}$ & $\begin{array}{c}\text { Средний } \\
\text { квадрат }\end{array}$ & F-Ratio & P-Value \\
\hline $\mathrm{A}: \mathrm{X}_{1}$ & 0,0336438 & 1 & 0,0336438 & 0,77 & 0,4439 \\
\hline $\mathrm{B}: \mathrm{X}_{2}$ & 0,0224061 & 1 & 0,0224061 & 0,52 & 0,5248 \\
\hline $\mathrm{AA}$ & 0,147392 & 1 & 0,147392 & 3,39 & 0,1629 \\
\hline $\mathrm{BB}$ & 0,00518207 & 1 & 0,00518207 & 0,12 & 0,7528 \\
\hline $\mathrm{R}^{2}, \%$ & \multicolumn{7}{|c|}{} \\
\hline
\end{tabular}

Примечание. F-Ratio - дисперсионное отношение Фишера; P-Value - уровень значимости.

$$
-86-
$$


Plot of y4

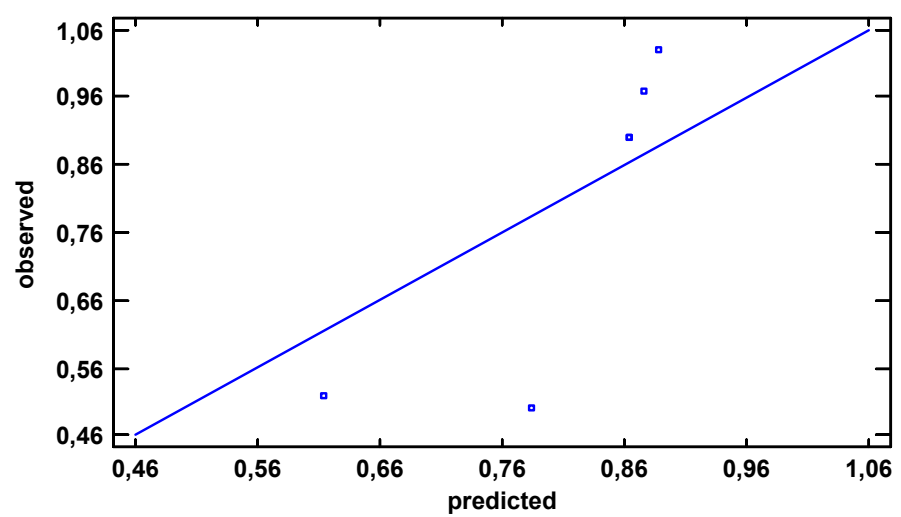

Рис. 6. Сравнение экспериментальных и расчетных значений сорбции бензола ( $\left.\mathrm{Y}_{4}\right)$ НУМ из лигнина древесины березы

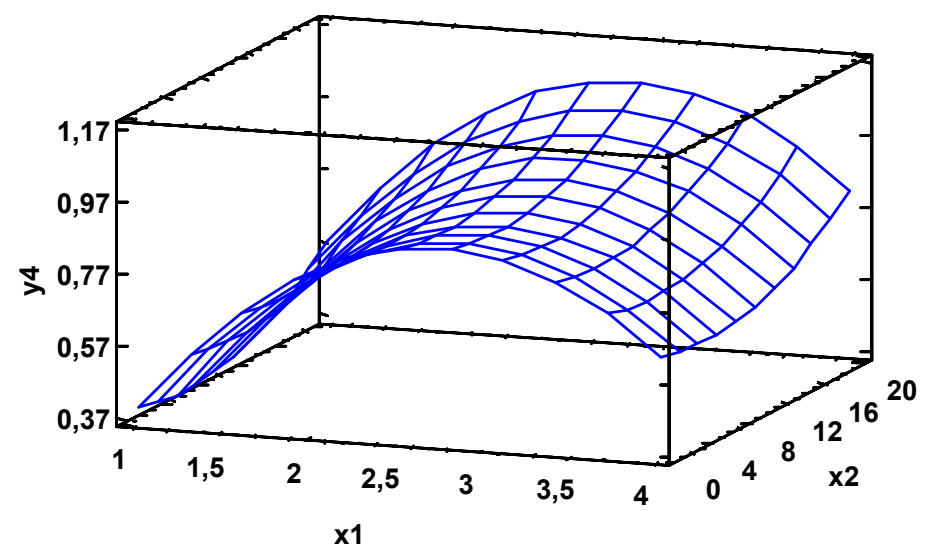

Рис. 7. Поверхность отклика зависимости сорбции бензола $\left(\mathrm{Y}_{4}\right)$ от условий процесса $\mathrm{X}_{1}$ и $\mathrm{X}_{2}$

\section{Заключение}

В результате проведенного экспериментально-статистического анализа были получены трехпараметрические математические модели, описывающие влияние основных исходных переменных (температура, продолжительность процесса и соотношение агентов) на выходные параметры нанопористых углеродных материалов, получаемых при термохимической активации гидроксидом калия лигнина, образующегося при каталитической делигнификации древесины березы.

На основании математического моделирования были определены условия получения НУМ с максимальной удельной поверхностью и объемом пор. Было установлено, что максимальное значение ( $2519 \mathrm{~m}^{2} /$ г) в пределах изученного факторного пространства прогнозируется при следующих условиях: соотношение КОН/лигнин 2,78 (по массе) и интенсивность нагрева $1{ }^{\circ} \mathrm{C} /$ мин. 
Максимальное прогнозируемое значение объема пор $\left(1,42 \mathrm{~m}^{3} / \Gamma\right)$ достигается согласно произведенным вычислениям по математической модели при соотношении КОН/лигнин 2,74 (по массе) и интенсивности нагрева $20^{\circ} \mathrm{C} /$ мин.

Рассчитаны условия термохимической активации лигнина древесины березы, позволяющие получить НУМ с максимальной сорбцией бензола. Было установлено, что максимальное значение сорбции бензола при этих условиях $(1,08$ г/г) в пределах изученного факторного пространства прогнозируется при соотношении КОН/лигнин 4,0 (по массе) и интенсивности нагрева $20^{\circ} \mathrm{C} /$ мин.

\section{Список литературы}

1. Camara Greiner E.O., Kalin T., Inoguchi Y., in "Activated Carbon, Chemical Economics Handbook", SRI Consulting, 2010, P. 5.

2. Ratnayake N. Sri Lankan Equities - Haycarb PLC (HAYC), John Keells Stockbrokers (Pvt) Ltd., Research Report, March. 2010. P. 1.

3. Gosselink R.J.A., deJong E., Guran B., Abacherli A. Coordination network for ligninstandardisation, production and applications adapted to market requirements // (EUROLIGNIN). Ind. Crops Prod. 2004. N20. P. 121-129.

4. Lora J.H., Glasser W.G. Recent industrial applications of lignin: a sustainable alternative to nonrenewable materials. J. Polym. Environ. 2002. N10. P. 39-48.

5. Mohan S.V., Karthikeyan J. Removal of lignin and tannin colour from aqueous solution by adsorption onto activated charcoal. Environ. Pollut. 1997. N97. P. 183-187.

6. Zhang Q., Chuang K.T. Adsorption of organic pollutants from effluents of a Kraft pulp mill on activated carbon and polymer resin. Adv. Environ. Res. 2001. N3. P. 251-258.

7. Stewart D. Lignin as a base material for materials applications: Chemistry, application and economics. Industrial crops and products. 2008. №27. Р. 202-207.

8. Симонова В.В., Шендрик Т.Г., Кузнецов Б.Н. Методы утилизации технических лигнинов. Журн. Сиб. федер. ун-та. Химия. 2010. Т.3 N4. С. 340-354.

9. Khitrin K.S., Fuks S.L., Khitrin S.V., Kazienkov S.A., Meteleva D.S. Lignin Utilization Options and Methods. Rossiiskii Khimicheskii Zhurnal. 2011. V.55. №1. P. 38-44.

10. Manimaran Ayyachamy, Finola E. Cliffe \& Jessica M. Coyne, Collier J., Tuohy M.G. Lignin: untapped biopolymers in biomass conversion technologies. Biomass Conv. Bioref. 2013. №3. P. 255 269.

11. Suhas S., Carrott P.J.M., Carrott M.M.L.R. Lignin - from natural adsorbent to activated carbon: A review. Bioresource Technology. 2007. N98. P. 2301-2312.

12. Кузнецов Б. Н. Актуальные направления химической переработки возобновляемой растительной биомассы. Химия в интересах устойчивого развития. 2011. Т.19. №1. С. 77-85.

13. Пен Р.3. Планирование эксперимента в Statgrachics. Красноярск: СибГТУ- Кларетианум, 2003. 246 с. 